\title{
Quantitative monitoring of WT1 expression in peripheral blood before and after allogeneic stem cell transplantation for acute myeloid leukemia - a useful tool for early detection of minimal residual disease
}

\author{
J. POLAK ${ }^{1, \star}$, H. HAJKOVA ${ }^{1}$, C. HASKOVEC ${ }^{1}$, H. CECHOVA ${ }^{1}$, I. MARINOV ${ }^{2}$, D. MIKULENKOVA ${ }^{3}$, J. MARKOVA ${ }^{4}$, M. MARKOVA $^{5}$, A. VITEK 5 , \\ V. VALKOVA ${ }^{5}$
}

${ }^{1}$ National Reference Laboratory for DNA Diagnostics Institute of Hematology and Blood Transfusion, Prague, Czech Republic; ${ }^{2}$ Flow cytometry laboratory Institute of Hematology and Blood Transfusion, Prague, Czech Republic; ${ }^{3}$ Morphology laboratory Institute of Hematology and Blood Transfusion, Prague, Czech Republic, ${ }^{4}$ Laboratory for PCR diagnostics of leukemias Institute of Hematology and Blood Transfusion, Prague, Czech Republic; ${ }^{5}$ Clinical department Institute of Hematology and Blood Transfusion, Prague, Czech Republic

*Correspondence: jaroslav.polak@uhkt.cz

Received January 31, 2012 / Accepted July 18, 2012

\begin{abstract}
Overexpressed Wilms tumor gene 1 (WT1) has been found in a majority of patients with acute myeloid leukemia (AML). The aim of this study was to confirm the applicability of WT1 expression measurement as a marker of minimal residual disease (MRD). The expression of WT1 gene was measured by real-time polymerase chain reaction in peripheral blood (PB) according to European Leukemia Net (ELN) recommendations. The WT1 expression was related to the expression of a reference gene Abelson (ABL) and the results were calculated as a number of WT1 copies related to $10^{4}$ copies of ABL gene. The upper normal limit of WT1 expression was set at 50 copies of WT1 to $10^{4}$ copies of ABL. Morphological, flow cytometry and chimerism examinations were evaluated according to standard protocols.

A total of 51 AML patients with overexpressed WT1 gene were analyzed. The median follow-up after transplantation was 14 (2-72) months. WT1 expression levels exceeding the upper normal limit were considered as a sign of impending hematological relapse, in accord with morphological, flow cytometry and chimerism data, as well as with the expression of the specific fusion genes. Moreover, in 7 patients the rise of WT1 expression preceded all other standard methods. Patients with high WT1 expression before allogeneic hematopoietic stem cell transplantation (allo-HSCT) had significantly worse outcome than patients with low WT1 level. Examination of WT1 expression in PB of patients with AML is a useful tool for MRD monitoring. Moreover, the WT1 gene expression before stem cell transplantation seems to be of prognostic significance.
\end{abstract}

Key words: WT1, MRD, allogeneic stem cell transplantation, acute myeloid leukemia

Allogeneic hematopoietic stem cell transplantation belongs to the effective therapeutic and potentially curative approach in the treatment of patients with AML. Unfortunately, many of transplanted patients suffer from disease relapse after transplantation. Moreover, in comparison to other hematological malignancies, occurrence of relapse in AML is relatively rapid. Therefore, early detection of relapse may provide an opportunity to use early therapeutic intervention as immunomodulation, including donor lymphocyte infusions (DLI), chemotherapy or its combination. MRD monitoring is an excellent tool for predicting relapse and could also serve as an important prognostic factor. A variety of methods with different sensitivity are available for MRD evaluating follow- ing allo-HSCT. These methods are based on morphological, flow cytometry and chimerism examination or on DNA/ mRNA methods, which measure expression of the specific chimeric leukemia markers by the real-time PCR methodology (RQ-PCR). The most sensitive specific markers in AML encompass especially fusion genes, e.g., RUNX1/RUNX1T1, CBFB/MYH11, MLL gene fusions, DEK/NUP214 and PML/ $\mathrm{RAR} \alpha$. The real-time polymerase chain reaction methodology is highly specific and sensitive and it can detect one cell bearing this specific transcript among $10^{4}-10^{6}$ normal cells [1]. Unfortunately, these specific markers are available only in approximately $40-50 \%$ of patients with acute myeloid leukemia [2]. However, leukemic cells often markedly overexpress 
so called leukemia associated antigens and monitoring of these nonspecific markers could serve as an alternative in the absence of the specific markers. WT1 gene as one of them has been found overexpressed in $90 \%$ of acute myeloid leukemia cells [3]. It is located on the chromosome 11p13 and primarily it was isolated as a gene responsible for Wilms tumor [4]. The WT1 gene is preferentially expressed during embryogenesis and its expression is restricted to a small number of normal tissues such as testicle, kidney, ovary, uterus and other. Apart from normal functions the WT1 gene is considered as an oncosuppressor gene deleted in pediatric patients with WAGR syndrome, Denys Drash syndrome and concurrently it acts as a transcription factor with high expression found in mesothelioma, glioblastoma and leukemia [5, 6]. 24 protein isoforms have been described, which increase or decrease the function of many genes for growth factors or their receptors and these functions are probably associated with oncogenic properties such as inhibition of apoptosis via p53 and Bcl-2 and differentiation of leukemic cells [7]. According to many observations $[8,9,10-15]$, the WT1 gene is considered as an appropriate MRD leukemic marker, and its expression in bone marrow or in peripheral blood correlates with disease status and reaches $10^{4}-10^{5}$ sensitivity of detection. Sensitivity and specificity of the WT1 quantification is of great importance, so huge effort was made in order to develop accurate and sensitive assay for WT1 quantification [16]. Beside the high expression of the WT1 gene at the time of diagnosis its expression is often elevated in advance of hematological relapse, which can be useful for early treatment approach. The aim of this study was to evaluate whether RQ-PCR monitoring of the WT1 gene expression in PB could serve as the MRD marker in acute leukaemia patients after allo-HSCT. Secondly, the prognostic significance of the WT1 expression before alloHSCT seems to be important.

\section{Patients and methods}

Patients. Overall 51 patients were enrolled in the study between April 2005 and December 2010. All the treatment protocols, data collection and analysis methods were approved by the Institutional Review Board and the patients gave signed informed consent. Patients' characteristics are shown in (table 1) and patients' transplant characteristics are depicted in (table 2). The patients were divided into 2 groups according to the pre-transplant WT1 expression level with respect to the upper normal limit of WT1 expression (table 1). The overall survival (OS) was defined as the period from the day of transplantation until the day of death from any cause. Relapse incidence (RI) was defined as the time period from transplantation until relapse or disease progression. The definition of complete remission and relapse followed recommended criteria [17]. Prognostic subgroups of AML based upon presented cytogenetics and genetic lesions are defined according recent recommendation [18].
Table 1. Patient characteristics

\begin{tabular}{cl}
\hline $\begin{array}{c}\text { Total number of patients } \\
\text { male }\end{array}$ & 51 \\
female & 19 \\
Age - median, years (range) & $48(21-63)$ \\
AML type (FAB) & M1 13x, M2 10x, M3 1x, M4 13x, M5 2x \\
& M6 3x, NA 7x \\
Karyotype normal & 23 \\
$\quad$ abnormal & 23 \\
$\quad$ NA $^{*}$ & 5 \\
Specific molecular marker & $(2 \times$ AML1/ETO, 5 x CBF $/$ MYH11, 2 x \\
& MLL/AF9, 1 x PML/RARa.) \\
WT1 status before HSCT & 18 positive, 32 negative, 1 NA \\
\hline *NA = not available &
\end{tabular}

${ }^{\star} \mathrm{NA}=$ not available

Table 2. Transplant characteristics

\begin{tabular}{|c|c|c|}
\hline & $14(27 \%)$ \\
\hline \multicolumn{2}{|c|}{$\begin{array}{l}\text { Disease status at transplant } C R 1 \\
\text { CR } 1 \text { (after salvage therapy, primary induction } \\
\text { failure) }\end{array}$} & $16(32 \%)$ \\
\hline & CR 2 & $15(29 \%)$ \\
\hline & active disease & $6(12 \%)$ \\
\hline \multirow[t]{4}{*}{ Donor } & $\mathrm{IS}^{*}$ & $14(27 \%)$ \\
\hline & Mismatched sibling & $1(2 \%)$ \\
\hline & MUD & $18(35 \%)$ \\
\hline & MMUD (1-2 allelic mismatches) & $18(35 \%)$ \\
\hline \multicolumn{2}{|c|}{ Conditioning myeloablative } & $40(78 \%)$ \\
\hline & reduced intensity & $11(22 \%)$ \\
\hline \multicolumn{2}{|c|}{ PBPC/BM+ } & $41 / 10(80 / 20 \%)$ \\
\hline
\end{tabular}

$\mathrm{CR}=$ complete remission, $\mathrm{IS}=$ identical sibling, $\mathrm{MM}=$ mismatch, $\mathrm{MUD}=$ matched unrelated donor, MMUD = mismatched unrelated donor, + PBPC $=$ peripheral blood progenitor cells, $\mathrm{BM}=$ bone marrow

Table 3. Follow-up

\begin{tabular}{lcl}
\hline Follow-up after HSCT- median (range), months & & $14(2-72)$ \\
Disease status after HSCT & CR & $32(63 \%)$ \\
& relapse & $17(33 \%)$ \\
Status of patients at last follow-up & not evaluable & $2(4 \%)$ \\
& alive & $33(65 \%)$ \\
Cause of death & death & $18(35 \%)$ \\
& relapse/progression & $13(25 \%)$ \\
& NRM & $5(10 \%)$ \\
\hline
\end{tabular}

$\mathrm{CR}=$ complete remission, $\mathrm{NRM}=$ non relapse mortality

Samples preparation. Ten million white blood cells from peripheral blood were isolated by the red cell lysis method. The cell sediment was lysed and stabilized by guanidine isothiocyanate. Total RNA was extracted by the method of Chomczynski and Sacchi [19] modified according to Polak et al. [20].

cDNA Synthesis. The total of $0,5-1 \mu \mathrm{g}$ isolated RNA was incubated with $50 \mathrm{pmol}$ of random hexamers at $65^{\circ} \mathrm{C}$ for 10 minutes to release the possible secondary structure. Subsequently, $120 \mathrm{U}$ of Mu-MLV reverse transcriptase (Promega, 


\section{OS by WT1 status before HSCT}

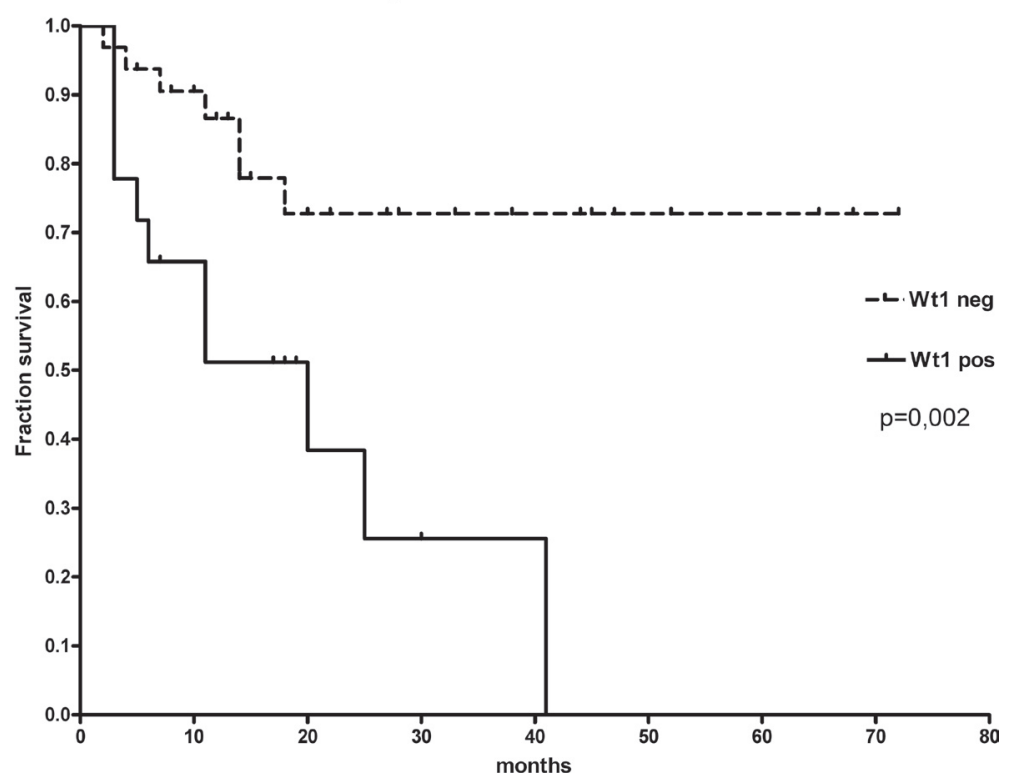

Figure 1. Overall survival according to the WT1 status before HSCT, months from HSCT

Madison, USA), 10 U of RNAse inhibitor RNAsin (Promega) and a mixture of deoxynucleotide triphosphates (final concentration $2.5 \mathrm{mM}$ each) were added in a total volume of $20 \mu \mathrm{l}$. Synthesis of cDNA was performed at $42^{\circ} \mathrm{C}$ for 60 minutes followed by heating at $95^{\circ} \mathrm{C}$ for 2 minutes.

Real-time PCR. The majority of the samples were analysed by the quantitative real-time PCR (RQ-PCR) of WT1 that was done by usage of the WT1 ProfileQuant KIT (Ipsogen S A., Marseille, France). The expression of the WT1 gene was related to the expression of the housekeeping gene $\mathrm{ABL}$ according to recommendations of ELN. Amplification and data analysis were carried out using the Rotor Gene 3000A thermocycler (Corbett Research, Sydney, Australia). The calibration curve, for quantitative assessment of WT1, was constituted by serial dilutions ranging from $10^{6}$ to $10^{1}$ molecules of a linearized plasmid obtained by cloning the target WT1 sequence. The results of WT1 expression are depicted as a number of WT1 copies related to $10^{4}$ copies of the reference gene ABL according to the manufacturer and ELN recommendations [16]. The sensitivity of this RQ-PCR method is defined as a possibility to detect 10 copies of WT1 gene. All samples were quantified in duplicates with defined measurement uncertainty and with appropriate negative control. In case of reference gene amplification, the samples with difference in particular $\mathrm{Ct}$, larger than 0,6 cycle (that means measurement uncertainty) were re-amplified. Similarly, the maximal allowed differences, in particular for $\mathrm{Ct}$ values, i.e. measurement uncertainty, were defined for the particular levels of WT1 expression. The minimal expression of the reference gene ABL threshold was 3000 copies - the samples with lower expression of ABL gene were omitted. According to ELN recommendations the upper normal limit of WT1 expression is equal to 50 copies WT1 $1 / 10^{4}$ copies of reference gene ABL in peripheral blood. The expression of WT1 was analysed before allo-HSCT. After allo-HSCT, the WT1 gene expression level was monitored every month in the first year and then four times per year, more often in case of relapse suspicion. Before introduction of the aforementioned protocol based on the ELN recommendations we had used the relative quantification of WT1 gene according to [20]. WT1 expression has been normalized to the ABL gene expression and results were depicted in relative units. Upper normal limit of 50 copies WT1/10000 copies ABL in ELN recommended protocol corresponds to relative $\mathrm{WT} 1$ expression $=0,02$ according to the protocol described in [20]. Both methods have been found highly significantly correlated $\mathrm{P}<0,0001$. The expression of fusion genes CBFB/MYH11, RUNX1/RUNX1T1, PML/RAR $\alpha$ and MLLT3/MLL was analysed according to previously described methods [20, 21].

Morphological, flow cytometry and molecular chimerism examination. Flow cytometry analysis was performed on a FACS Aria III instrument equipped with FACS Diva v6.1.3 software and set up with CS\&T calibration beads. Leukemia associated phenotypes (LAPs) were established in newly diagnosed AML and monitored using the following 4 tube/ 8 colour panel of monoclonal antibodies directly conjugated to Pacific Blue, Horizon V500, FITC, PE, PE-Cy5.5, PE-Cy7, APC and APC-H7 respectively:

1. HLA-DR/CD45/CD2/CD13/CD34/CD117/CD7/CD14, 2. HLA-DR/CD45/CD36/CD56/CD34/CD117/CD22/CD19, 


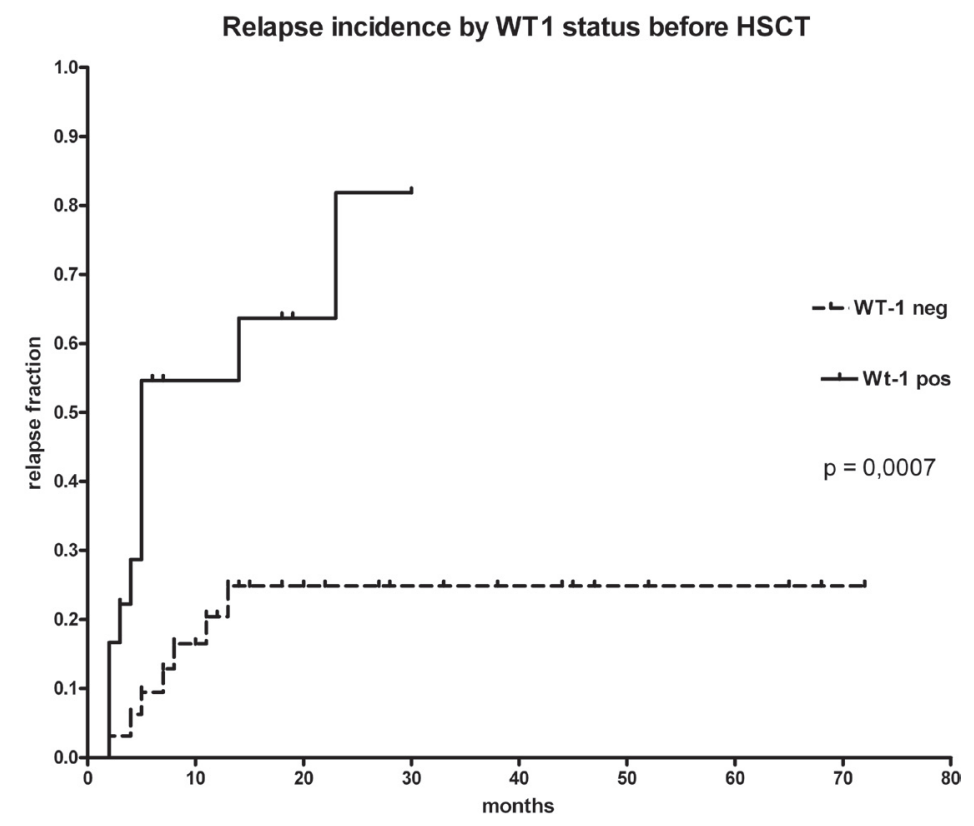

Figure 2. Relapse incidence according to the WT1 status before HSCT, months from HSCT

3. HLA-DR/CD45/ CD15/CD33/CD34/CD117/CD11b/ CD14, 4. HLA-DR/CD45/ CD65/CD123/CD34/CD117/ CD38/ CD14. LAPs were identified in the CD45 low/SSClow/CD34+ and /or CD117+ WBC compartment, following acquisition of at least 500000 events. MRD\% was corrected for the percentage of LAPs expression on leukemic blasts at diagnosis as described by Feller et al. [22].

Chimerism was analysed by quantitative determination of informative DNA polymorphisms that included VNTRs (variable number of tandem repeats) STRs (short tandem repeats) and sex-specific loci using standard protocols [23]. Complete chimerism was defined as $>99 \%$ donor's hematopoietic stem cells in recipient's bone marrow or peripheral blood.

CR was defined as absence of any tumor and $<5 \%$ BM blasts with polymorphonuclear cells $>1.10^{9} / \mathrm{L}$, platelets $>100$. $10^{9} / \mathrm{L}$ and independence of transfusion. Partial remission was defined as 5-15\% blasts in BM of adequate cellularity with evidence of trilineage regeneration. Patients who did not meet the criteria for CR or PR were categorized as resistant. Definition of response to therapy before and after transplantation was expressed according to the published criteria. [24]

Statistics. Estimation of median expression was performed by GraphPad Prism 4 column statistics.

Kaplan - Meier curves and two-sided long-rank test were used to estimate the distribution of overall survival and relapse incidence and to compare difference between survival curves. The tests were conducted at a level of significance of 0.05 . Expression of specific chimeric fusion genes were correlated by using linear regression of GraphPad Prism4 software. Categorical patient characteristics were compared by using
Fisher's exact test and Pearson Chi-Square test, continuous characteristics were compared with the two-sample $t$ test.

\section{Results}

After successful allo-HSCT, 32 patients remained in longterm remission and their WT1 expression stayed bellow the upper normal limit (fig. 3), i.e., low level; simultaneously the other markers i.e. morphologic, flow cytometry and chimerism examination were negative. Therefore we established complete agreement between low WT1 level, full donor chimerism (100\%) and negativity by flow cytometry. On the other hand, many of followed patients $(n=17)$ relapsed with simultaneous rise of the WT1 expression (median of WT1 expression in relapse was 3126 copies WT1/10 ${ }^{4}$ copies ABL) above upper normal limit (fig.4). The WT1 gene expression rose not only together with morphologic, flow cytometry and chimerism findings, its expression even preceded expression of these markers with a median of 0.99 months (range: $0,69-1,87$ ) in the follow-up samples of 7 patients (fig. 5 and table 4). A subset of patients $(n=10)$ displayed the presence of the specific fusion genes, i.e., CBFB/MYH11, RUNX1/RUNX1T1, PML/RARa and MLLT3/MLL. The close agreement between expression of WT1 and morphologic, flow cytometry and chimerism findings points to a highly significant correlation of the WT1 gene expression and of the fusion genes: $(\mathrm{P}<0.0001)$ in case of the CBFB/MYH11 fusion gene, the RUNX1/RUNX1T1 fusion gene $(\mathrm{P}=0.0114)$ and the MLLT3/MLL fusion gene $(\mathrm{P}<0.0001)$ (fig. 6). On the other hand, in one examined patients the expression of the PML/RARa fusion gene did not correlate 


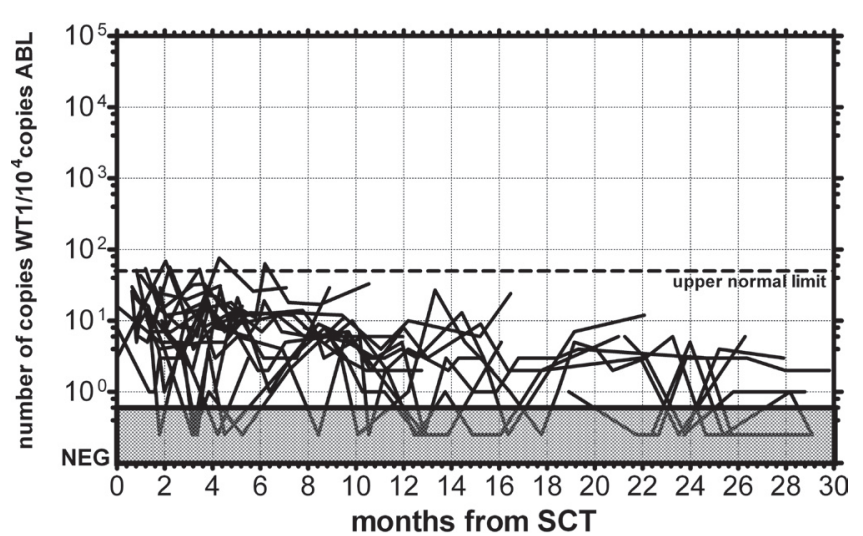

Figure 3. Monitoring of MRD of AML patients in permanent remission after HSCT by measuring relative expression of the WT1 gene in peripheral blood. The dotted line represents the upper normal limit.

with the WT1 expression. A total of 17 patients relapsed and 13 of relapsed patients died afterwards (tab. 3). Four relapsed patients were successfully treated by chemotherapy and DLI and they reached complete remission with simultaneous decline of the WT1 expression bellow the upper normal limit. Some relapsed patients $(n=2)$ showed a relative slow increase of the WT1 expression with a longer WT1 expression doubling

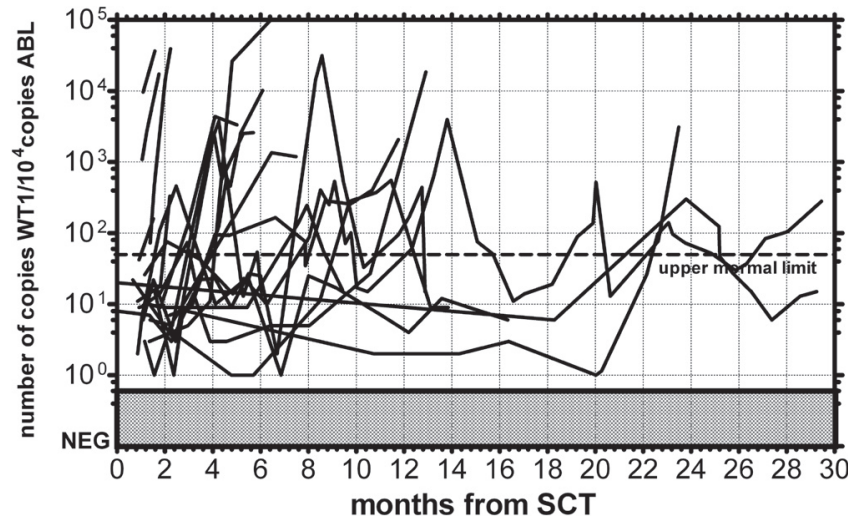

Figure 4. MRD monitoring of AML patients who relapsed after HSCT by measuring relative expression of the WT1 gene in peripheral blood. The dotted line represents the upper normal limit.

time. These patients might be the appropriate candidates for early immunomodulatory intervention (i.e., tapering of immunosuppressive therapy and/or DLI); the rest of the patients relapsed more rapidly with the short WT1 doubling time. For purposes of additional comparison we divided patients according to the WT1 expression level before transplantation. Both groups, i.e., WT1 positive patients before transplantation and

Table 4. Summary of 7 patients where the WT1 rised before positivity of morfology evaluation, chimerism and/or flow cytometry (FCM) . The calculated predetection of WT1 expression is in "predetection by WT1“ column. Donor chimerism is depicted in percentage of the donor haemopoiesis. WT1 expression is measured in number of WT1 copies/10 $10^{4}$ copies ABL. 50 copies of WT1/10 ${ }^{4} \mathrm{ABL}$ is the upper normal limit, HSCT is hematopoietic stem cell transplantation, micro means microchimerism.

\begin{tabular}{|c|c|c|c|c|c|c|}
\hline Patient n. & $\begin{array}{c}\text { months since } \\
\text { HSCT }\end{array}$ & WT1 & morphology & FCM & $\begin{array}{l}\text { chimerism } \\
\text { percentage }\end{array}$ & $\begin{array}{c}\text { Predetection } \\
\text { by WT1 (months) }\end{array}$ \\
\hline \multirow[t]{3}{*}{ Patient n. 1} & 11,04 & 96 & neg & neg & 100 & \\
\hline & 11,96 & 1258 & & & 100 & \\
\hline & 12,91 & 18458 & pos & pos & 85 & 1,87 \\
\hline \multirow[t]{3}{*}{ Patient n. 2} & 12,32 & 60 & & & 100 & \\
\hline & 13,24 & 632 & & & micro & \\
\hline & 13,80 & 3979 & pos & neg & 93 & 1,48 \\
\hline \multirow[t]{4}{*}{ Patient n. 3} & 1,38 & 73 & & & 100 & \\
\hline & 1,55 & 460 & neg & neg & 100 & \\
\hline & 2,01 & 14428 & & & 97 & \\
\hline & 2,24 & 39409 & pos & pos & 63 & 0,86 \\
\hline \multirow[t]{4}{*}{ Patient n. 4} & 4,25 & 124 & neg & neg & 97 & \\
\hline & 4,58 & 609 & & & & \\
\hline & 4,74 & 460 & & & 100 & \\
\hline & 5,17 & 2568 & pos & pos & 97 & 0,92 \\
\hline \multirow[t]{3}{*}{ Patient n. 5} & 9,72 & 280 & & & 97 & \\
\hline & 10,84 & 373 & & & & \\
\hline & 11,46 & 556 & pos & pos & 85 & 1,74 \\
\hline \multirow[t]{2}{*}{ Patient n. 6} & 1,78 & 110 & & & 99 & \\
\hline & 2,47 & 459 & pos & pos & 92 & 0,69 \\
\hline \multirow[t]{3}{*}{ Patient n. 7} & 11,76 & 95 & neg & neg & 99 & \\
\hline & 12,22 & 170 & neg & neg & 99 & \\
\hline & 12,75 & 442 & neg & neg & micro & 0,99 \\
\hline
\end{tabular}


relapsed patients after SCT

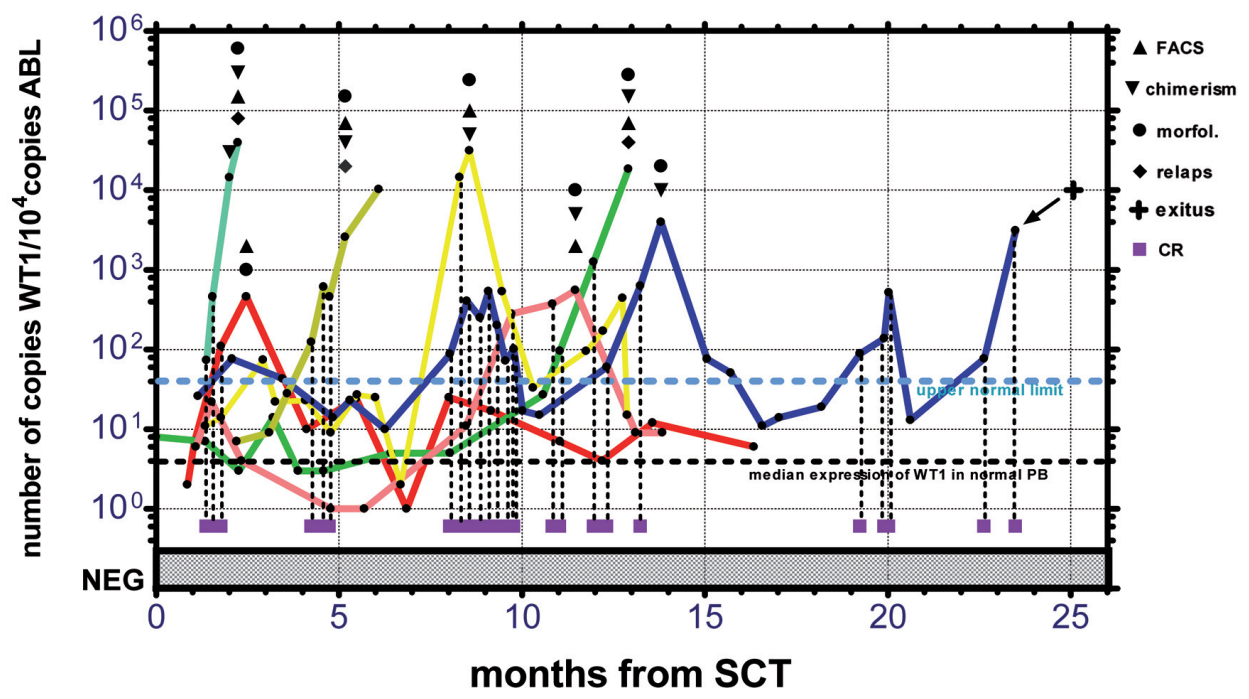

Figure 5. MRD monitoring of AML patients who relapsed after HSCT by measuring relative expression of the WT1 gene and by morphology, flow cytometry and molecular chimerism in peripheral blood.

expresion of WT1 and CBFB/MYH11
in patient subtype: AML M4

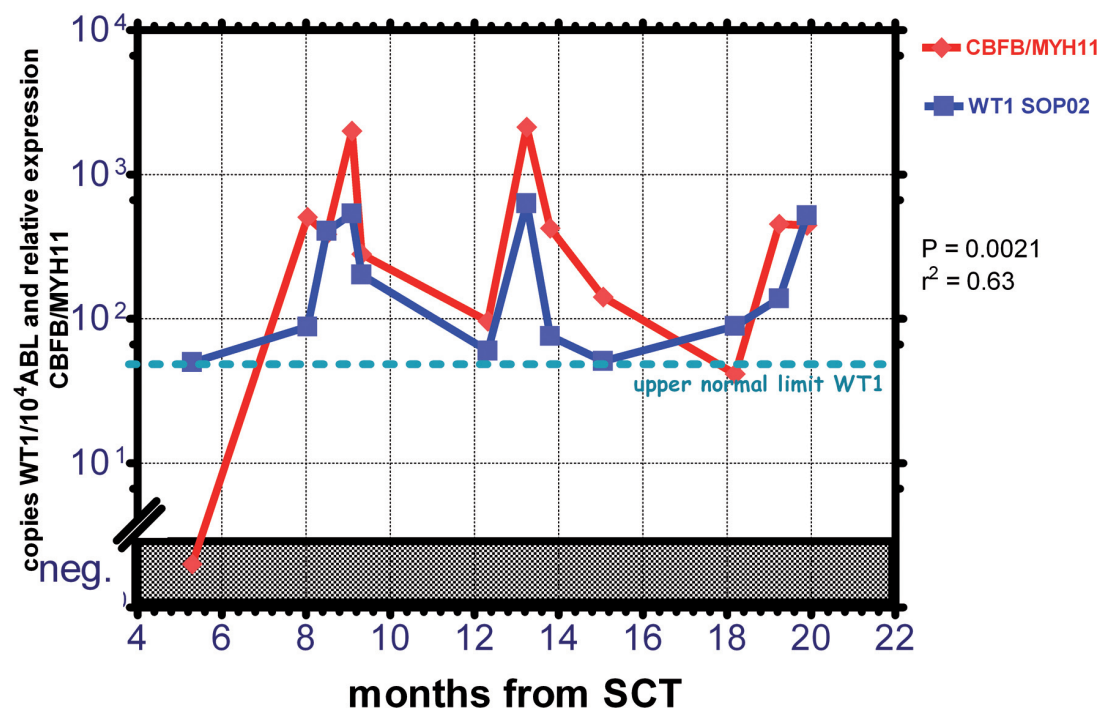

Figure 6. MRD monitoring of AML patient by WT1 expression and by expression of CBFB/MYH11 fusion gene

WT1 negative patients before transplantation were compared in terms of followed parameters: age, sex, FAB subtype, disease status at allo-HSCT, donor type, graft type, conditioning regimen, incidence of acute and chronic GVHD and finally genetic risk. There have not been found statistically significant differences. We have found that the patients with a high pretransplant level (WT1 positive) of the WT1 gene $(n=18)$ compared to those with low expression of the WT1 gene (WT1 negative) $(\mathrm{n}=32)$ differ significantly in terms of overall survival and relapse incidence. The overall survival was significantly longer in patients with low WT1 expression before allo-HSCT (OS in 3 -years $26 \%$ vs. $73 \%$ ( $\mathrm{p}=0,002)$ (fig. 1): Hazard ratio: $0,238395 \% \mathrm{CI}$ of ratio (0.06128 to 0.4988 ). Analogously, relapse incidence was higher in patients with high pre-trans- 
plantation level of the WT1 expression (cumulative RI in 3 years $82 \%$ vs. $25 \%$ ( $\mathrm{p}=0,007$ ) (fig. 2): Hazard Ratio 0,2350 $95 \% \mathrm{CI}$ of ratio $0,05284-0,4571$. The follow up data and disease status are depicted in (table 3 ).

\section{Discussion}

The determination and accurate assessment of MRD in AML patients is very important, because relapse remains the main cause of treatment failure $[25,26]$. Data obtained from MRD analysis allow to determinate the disease status and could predict impending relapse in advance. The chimeric fusion genes: CBFB/MYH11, RUNX1/RUNX1T1, PML/ RAR $\alpha$ and translocations involving MLL gene are widely used for MRD evaluation [27-31]. Using the real-time PCR quantification approach, the sensitivity of detection of one leukemic cell among $10^{5}$ to $10^{6}$ normal cells can be reached. Unfortunately, $50-60 \%$ of adult acute leukaemia patients lack these specific markers, and morphological, flow cytometry and chimerism examination have lower sensitivity compared to specific real-time PCR methods. Intensive effort has been done to find an alternative nonspecific marker of MRD. The WT1 gene has been found to be highly overexpressed in the majority of AML; it may serve as nonspecific marker. Therefore, it could be applied particularly to those AML patients who lack specific markers. The expression of the WT1 gene was described as a useful marker of MRD in AML patients due to its high specificity, sensitivity and most importantly to its broad applicability by many authors $[8,9,10-15]$. There exist some controversies concerning the use of the WT1 gene for MRD monitoring, especially after allo-HSCT [32]. The above-cited study did not confirm the use of the WT1 gene as a suitable MRD marker; on the other hand, this study was based on the application of the qualitative PCR in contrast to the real-time PCR, which is generally more specific and sensitive and allows accurate quantification. The second obstacle was the WT1 expression in the subset of normal CD34 positive cells from peripheral blood of healthy donors [33]. That is why a strict cut-off value must be determined to distinguish normal expression from an abnormal one. Our protocol is based on the highly specific and sensitive RQ-PCR quantification of the WT1 gene expression in peripheral blood samples, based on the recommended ELN protocol. In this protocol the upper normal limit of the WT1 expression had been determined and validated by the multicenter study [16] in order to eliminate the above obstacle with WT1 expression in a subset of normal CD34+ cells. Exceeding this limit, in fact the molecular relapse level, predicts impending relapse. ELN multicenter study therefore introduced a highly sensitive and reliable tool to distinguish normal expression from the aberrant one. Another requisite parameter in MRD follow-up is a proper determination of the time schedule for measurement of WT1 expression [34]. All our patients were analysed at the time of diagnosis and/or in relapse, to determine the information value of the WT1 expression. The majority of patients were followed at least once per month following transplantation during the first year. In case of risk patients with the persistent MRD before transplantation is WT1 followed 2 times per month in early postransplant period (up to 3 months). Secondly, the more frequent monitoring of WT1 expression is recommended in case of suspected relapse. We observed an absolute correlation between increased WT1 expression and the positivity with alternative methods, i.e., polychromatic flow cytometry and molecular chimerism examination. In addition, as also described in another study [24], the WT1 expression grew earlier than the other markers. Approximately 40-50\% AML patients express chimeric fusion genes and their expression significantly correlated with expression of the WT1 gene [ 10 , $8,15]$. In our setting, we found the expression of the WT1 gene in a highly significant correlation with the expression of specific fusion genes (except for one patient bearing the PML/RARa fusion gene), confirming the applicability of our approach. The evaluation of the WT1 expression after allo-HSCT seems to be a useful tool for ascertaining the disease status in agreement with published data $[2,25,26]$. Similarly to other authors we found a correlation between the pretransplatation WT1 level and prognosis [26]. The overall survival of patients with high pretransplant level of the WT1 expression was significantly worse than that of patients with low expression of the WT1 gene; also, patients with high expression of the WT1 before transplantation displayed higher cumulative incidence of relapse. A certain limitation of our study is the fact, that WT1 gene analysis was performed in peripheral blood. According to published data [34] it is more suitable to measure the WT1 gene expression in bone marrow samples, because the impending relapse is detectable sooner than in peripheral blood samples. This problem could be solved by more frequent sampling after HSCT as recommended by [34], i.e., 2 times per month. Moreover, examination from peripheral blood is less stressful for the patients than bone marrow aspiration. Consequently, when our molecular relapse border was exceeded, we performed further analysis as soon as possible, in order to confirm or exclude the impending relapse of disease. Our study encompasses a relative low number of patients to allow more precise analysis of the impact of the other factors like type of conditioning regimen used or impact of AML prognostic markers like presence of FLT3/ITD or the other molecular or cytogenetic prognostics markers. In our study we confirmed the significance of accurate measurement of the WT1 gene expression level in peripheral blood after allo-HSCT as a specific and highly sensitive MRD marker. Early detection of MRD allows early therapeutic intervention, especially in patients with slow WT1 expression increase. Moreover, WT1 expression immediately before transplantation seems to be of a prognostic importance analogically to the prognostic significance of WT1 expression at diagnosis [35]. Therefore we consider WT1 monitoring to be an essential approach to detect and manage impending relapse in AML patients after 
allo-HSCT. Particularly, the prognostic importance of the pre-transplant WT1 level is of important significance and it needs to be confirmed on more patients in further studies in order to validate our results.

Acknowledgements: This work was supported by IGA MZ CR grant: NR 8748-3 and by scientific project MZ 00023736

\section{References}

[1] GARG M, MOORE H, TOBAL K, YIN JAL. Prognostic significance of quantitative analysis of WT1 gene transcripts by competitive reverse transcription polymerase chain reaction in acute leukaemia. British Journal of Haematology 2003; 123: 49-59. http://dx.doi.org/10.1046/j.1365-2141.2003.04552. $\underline{\mathrm{X}}$

[2] OGAWA H, TAMAKI H, IKEGAME K, SOMA T, KAWAKAMI M et al. The usefulness of monitoring WT1 gene transcripts for the prediction and management of relapse following allogeneic stem cell transplantation in acute type leukemia. Blood 2003; 101: 1698-1704. http://dx.doi.org/10.1182/blood2002-06-1831

[3] MIWA H, BERAN M, SAUNDERS GF. Expression of the Wilms-Tumor Gene (Wt1) in Human Leukemias. Leukemia 1992; 6: 405-409.

[4] CALL KM, GLASER T, ITO CY, BUCKLER AJ, PELLETIER $\mathrm{R}$ et al. Isolation and Characterization of A Zinc Finger Polypeptide Gene at the Human Chromosome-11 Wilms Tumor Locus. Cell 1990; 60: 509-520. http://dx.doi. org/10.1016/0092-8674(90)90601-A

[5] ALGAR E. A review of the Wilms' tumor 1 gene (WT1) and its role in hematopoiesis and leukemia. Journal of Hematotherapy \& Stem Cell Research 2002; 11: 589-599. http://dx.doi. org/10.1089/15258160260194749

[6] LOEB DM, SUKUMAR S. The role of WT1 in oncogenesis: Tumor suppressor or oncogene? International Journal of Hematology 2002; 76: 117-126. http://dx.doi.org/10.1007/ BF02982573

[7] SCHARNHORST V, VAN DER EB AJ, JOCHEMSEN AG. WT1 proteins: functions in growth and differentiation. Gene 2001; 273: 141-161. http://dx.doi.org/10.1016/S03781119(01)00593-5

[8] CILlONI D, GOTTARDI E, DE MICHELI D, SERRA A, VOLPE G et al. Quantitative assessment of WT1 expression by real time quantitative PCR may be a useful tool for monitoring minimal residual disease in acute leukemia patients. Leukemia 2002; 16: 2115-2121. http://dx.doi.org/10.1038/ sj.leu. 2402675

[9] CILLONI D, RENNEVILLE A, HERMITTE F, HILLS RK, DALY S et al. Real-time quantitative PCR (RQ-PCR) detection of minimal residual disease (MRD) by optimized WT1 assay to enhance risk stratification in acute myeloid leukemia (AML): A European leukemia net study. Blood 2007; 110: 167A. [10] Inoue K, Sugiyama H, Ogawa H, Nakagawa M, Yamagami T et al. WT1 As A New Prognostic Factor and A New Marker for the Detection of Minimal Residual Disease in Acute-Leukemia. Blood 1994; 84: 3071-3079.
[11] INOUE K, OGAWA H, YAMAGAMI T, SOMA T, TANI Y et al. Long-term follow-up of minimal residual disease in leukemia patients by monitoring WT1 (Wilms tumor gene) expression levels. Blood 1996; 88: 2267-2278.

[12] KREUZER KA, SABOROWSKI A, LUPBERGER J, APPELT C, NA IK et al. Fluorescent 5 '-exonuclease assay for the absolute quantification of Wilms' tumour gene (WT1) mRNA: implications for monitoring human leukaemias. Br.J.Haematol. 2001; 114: 313-318Hosen N, Sonoda Y, Oji $\mathrm{Y}$ et al. Very low frequencies of human normal CD34(+) haematopoietic progenitor cells express the Wilms' tumour gene WT1 at levels similar to those in leukaemia cells. British Journal of Haematology 2002; 116: 409-420. http://dx.doi. org/10.1046/j.1365-2141.2002.03261.x

[13] TRKA J, KALINOVA M, HRUSAK O, ZUNA J, KREJCI O et al. Real-time quantitative PCR detection of WT1 gene expression in children with AML: prognostic significance, correlation with disease status and residual disease detection by flow cytometry. Leukemia 2002; 16: 1381-1389. http://dx.doi. org/10.1038/sj.leu.2402512

[14] MENSSEN HD, SIEHL JM, THIEL E. Wilms tumor gene (WT1) expression as a panleukemic marker. International Journal of Hematology 2002; 76: 103-109. http://dx.doi. org/10.1007/BF02982571

[15] OSTERGAARD M, OLESEN LH, HASLE H, KJELDSEN E, HOKLAND P. WT1 gene expression: an excellent tool for monitoring minimal residual disease in $70 \%$ of acute myeloid leukaemia patients - results from a single-centre study. British Journal of Haematology 2004; 125: 590-600. http://dx.doi. org/10.1111/j.1365-2141.2004.04952.x

[16] CILLONI D, RENNEVILLE A, HERMITTE F, HILLS RK, DALY S et al. Real-Time Quantitative Polymerase Chain Reaction Detection of Minimal Residual Disease by Standardized WT1 Assay to Enhance Risk Stratification in Acute Myeloid Leukemia: A European LeukemiaNet Study. Journal of Clinical Oncology 2009; 27: 5195-5201. http://dx.doi.org/10.1200/ LCO.2009.22.4865

[17] DOHNER H, ESTEY EH, AMADORI S, APPELBAUM FR, BUCHNER $T$ et al. Diagnosis and management of acute myeloid leukemia in adults: recommendations from an international expert panel, on behalf of the European LeukemiaNet. Blood 2010; 115: 453-474. http://dx.doi.org/10.1182/blood2009-07-235358

[18] FORAN JM. New prognostic markers in acute myeloid leukemia: perspective from the clinic. Hematology Am Soc Hematol Educ Program. 2010; 2010: 47-55. [19] Chomczynski P, Sacchi N. Single-step method of RNA isolation by acid guanidinium thiocyanate-phenol-chloroform extraction. Anal. Biochem. 1987; 162: 156-159. http://dx.doi.org/10.1016/00032697(87)90021-2

[20] POLAK J, MARKOVA J, SCHWARZ J, MAALOUFOVA J, VOLKOVA $Z$ et al. The use of quantitative assessment of Wilms tumour gene 1 for monitoring of residual disease in acute myeloid leukemia patients. Cas.Lek.Cesk. 2006; 145: 36-42. in Czech. [21] Markova J, Markova J, Trnkova Z, Michkopa P, Maaloufova J et al. Monitoring of minimal residual disease in patients with core binding factor acute 
myeloid leukemia and the impact of C-KIT, FLT3, and JAK2 mutations on clinical outcome. Leuk.Lymphoma 2009; 50: 1448-1460. http://dx.doi.org/10.1080/10428190903085951

[22] FELLER N, VAN DER POL MA, VAN STIJN A, WEIJERS GW, WESTRA AH et al. MRD parameters using immunophenotypic detection methods are highly reliable in predicting survival in acute myeloid leukaemia. Leukemia 2004; 18: 1380-1390. http://dx.doi.org/10.1038/sj.leu.2403405

[23] FORMANKOVA R, HONZATKOVA L, SIEGLOVA Z, STARY J, SEDLACEK P et al. Detailed monitoring of hematopoietic chimerism in a child treated by adoptive immunotherapy for high risk of relapse after BMT for acute myeloid leukemia. Bone Marrow Transplant. 2000; 25: 453-456. http://dx.doi. org/10.1038/sj.bmt.1702146

[24] CHESON DB, BENNETT JM, KOPECKY KJ, BUCHNER T, WILLMAN CL et al. Revised recommendations of the international Working Group for Diagnosis, Standardisation of response Criteria, Treatment outcomes, and reporting Standards for therapeutic Trials in acute myeloid leukemia. J. Clin. Oncol. 2003; 21: 462-9

[25] CANDONI A, TIRIBELLI M, TOFFOLETTI E, CILLONI D, CHIARVESIO A et al. Quantitative assessment of WT1 gene expression after allogeneic stem cell transplantation is a useful tool for monitoring minimal residual disease in acute myeloid leukemia. European Journal of Haematology 2009; 82: 61-68. http://dx.doi.org/10.1111/j.1600-0609.2008.01158.x

[26] JACOBSOHN DA, TSE WT, CHALEFF S, RADEMAKER A, DUERST R et al. High WT1 gene expression before haematopoietic stem cell transplant in children with acute myeloid leukaemia predicts poor event-free survival. British Journal of Haematology 2009; 146: 669-674. http://dx.doi.org/10.1111/ j.1365-2141.2009.07770.x

[27] MARCUCCI G, CALIGIURI MA, DOHNER H, ARCHER KR, SCHLENK RF et al. Quantification of CBF beta/MYH11 fusion transcript by Real Time RT-PCR in patients with INV(16) acute myeloid leukemia. Leukemia 2001; 15: 10721080. http://dx.doi.org/10.1038/sj.leu.2402159

[28] SCHNITTGER S, WEISSER M, SCHOCH C, HIDDEMANN W, HAFERLACH T et al. New score predicting for prognosis in PML-6RARA(+), AML1-ETO+, or CBFB-MYH11(+) acute myeloid leukemia based on quantification of fusion transcripts. Blood 2003; 102: 2746-2755. http://dx.doi. org/10.1182/blood-2003-03-0880
[29] TOBAL K, NEWTON J, MACHETA M, CHANG J, MORGENSTERN $\mathrm{G}$ et al. Molecular quantitation of minimal residual disease in acute myeloid leukemia with $t(8 ; 21)$ can identify patients in durable remission and predict clinical relapse. Blood 2000; 95: 815-819.,

[30] VISANI G, BUONAMICI S, MALAGOLA M, ISIDORI A, PICALUGA PP et al. Pulsed ATRA as single therapy restores long-term remission in PML-RAR alpha-positive acute promyelocytic leukemia patients: real time quantification of minimal residual disease. A pilot study. Leukemia 2001; 15: 1696-1700. http://dx.doi.org/10.1038/sj.leu.2402266

[31] OSUMI K, FUKUI T, KIYOI H, KASAI M, KODERA Y et al. Rapid screening of leukemia fusion transcripts in acute leukemia by real-time PCR. Leukemia \& Lymphoma 2002; 43: 2291-2299 Ommen HB, Schnittger S, Jovanovic JV et al. Strikingly different molecular relapse kinetics in NPM1c, PML-RARA, RUNX1-RUNX1T1, and CBFB-MYH11 acute myeloid leukemias. Blood 2010; 115: 198-205. http://dx.doi. org/10.1182/blood-2009-04-212530

[32] ELMAAGACLI AH, BEELEN DW, TRENSCHEL R, SCHAEFER UW. The detection of wt-1 transcripts is not associated with an increased leukemic relapse rate in patients with acute leukemia after allogeneic bone marrow or peripheral blood stem cell transplantation. Bone Marrow Transplantation 2000; 25: 91-96. http://dx.doi.org/10.1038/sj.bmt.1702095

[33] HOSEN N, SONODA Y, OJI Y, KIMURA T, MINAMIGUCHI $\mathrm{H}$ et al. Very low frequencies of human normal CD34(+) haematopoietic progenitor cells express the Wilms' tumour gene WT1 at levels similar to those in leukaemia cells. British Journal of Haematology 2002; 116: 409-420. http://dx.doi. org/10.1046/j.1365-2141.2002.03261.x

[34] OMMEN HB, NYVOLD CG, BRAENDSTRUP K, ANDERSEN BL, OMMEN IB et al. Relapse prediction in acute myeloid leukaemia patients in complete remission using WT1 as a molecular marker: development of a mathematical model to predict time from molecular to clinical relapse and define optimal sampling intervals. British Journal of Haematology 2008; 141: 782-791. http://dx.doi.org/10.1111/ j.1365-2141.2008.07132.x

[35] BERGMANN L, MIETHING C, MAURER U et al. High levels of Wilms' tumor gene (wt1) mRNA in acute myeloid leukemias are associated with a worse long-term outcome. Blood 1997; 90: 1217-1225. 